Michie Jay D. Simtoco, MD

Samantha Soriano-Castaneda, $\mathrm{MD}^{1,2,3}$

Daniel M. Alonzo, MD'

Maria Rina T. Reyes-Quintos, MD, MClinAud ${ }^{1,4}$

'Department of Otolaryngology Head and Neck Surgery The Medical City

${ }^{2}$ Department of Otolaryngology Head and Neck Surgery Rizal Medical Center

${ }^{3}$ Department of Otolaryngology Head and Neck Surgery Jose Reyes Memorial Medical Center

${ }^{4}$ Department of Otorhinolaryngology College of Medicine - Philippine General Hospital University of the Philippines Manila
Correspondence: Michie Jay D. Simtoco, MD

Department of Otolaryngology Head and Neck Surgery

The Medical City

Ortigas Avenue, Pasig City 1600

Philippines

Telefax: (+632) 6873349

Email:mjaymd@gmail.com

Reprints will not be available from the author.

No funding support was received for this study. The authors signed a disclosure that they have no proprietary or financial interests with any organization that may have direct interest in the subject matter of this manuscript, or in any product used or cited in this report.

Presented at the Interesting Case Contest, Philippine Society of Otolaryngology- Head and Neck Surgery Convention, Cagayan De Oro City May 2, 2008.

\title{
Fractured Tracheostomy Tube Ingestion in a Pediatric Patient
}

\section{ABSTRACT}

Objective: To report a case of fractured tracheotomy tube ingestion in a pediatric patient, discussing the clinical presentation, complications and management of tracheobronchial tree versus upper digestive tract foreign bodies.

\section{Methods:}

Design: Case Report

Setting: Tertiary Private Hospital

Patient: One

Result: A 4-year-old male child with unusual hypersensitivity to routine tracheotomy suctioning was discovered to have a fractured tracheotomy tube. Emergency radiographs localized the cannula in the abdomen and bronchoscopy was deferred. The foreign body was eventually passed out after four days.

Conclusion: Due diligence in diagnostics prior to bronchoscopy led to the avoidance of an unnecessary and sometimes complicated procedure. In developing countries with poor access to health care, the importance of regular tracheotomy follow-ups and periodic replacement cannot be overemphasized. A search of the English literature using Pubmed and Ovid search engines with keywords tracheostomy, foreign bodies and pediatrics confirms that this is the first reported accidental ingestion of a fractured tracheotomy tube in a pediatric patient.

Key words: Tracheostomy, Complications, Foreign bodies, Pediatrics

Tracheotomy is one of the most commonly performed surgical procedures for airway management. Among its rarest complications is tracheotomy tube breakage and aspiration of various components into the tracheobroncial tree. ${ }^{1,2}$ To our knowledge, there are no reports of subsequent ingestion of a fractured tracheostomy tube component in the English literature. We report the first such case in a pediatric patient with a long-standing tracheotomy tube.

\section{Case Report}

An 8-month-old boy diagnosed with muscular dystrophy underwent tracheotomy for long-term ventilator support. His follow-up visits were few and far between and the originally-inserted Shiley ${ }^{\circledR}$ (Tyco Healthcare Group LP in Pleasanton, CA) pediatric size 
3 tracheostomy tube had never been replaced until we saw him at 4 years of age.

A few hours prior, he was noted to be unusually hypersensitive to routine tracheostomy tube suctioning. The mother lifted the tracheostomy tube slightly to adjust it and discovered that the cannula was missing. Thinking the broken tube may have been coughed out, a thorough search was conducted in the vicinity, but it was nowhere to be found and he was rushed to the emergency room. No coughing or stridor was observed.

On admission, the boy was comfortable with stable vital signs and oxygen saturations of $95 \%-97 \%$. He was slightly tachypneic with minimal inspiratory stridor, shallow subcostal retractions and wheezing over both lung fields. The outer flange of the tracheostomy tube was in place, but careful lifting confirmed that the cannula was missing. (Figures 1 and 2)

Thinking the fractured cannula could be in the airway, preparations were made for emergency bronchoscopy, including routine chest radiographs. To everyone's surprise, they revealed the tracheotomy tube cannula in the left upper quadrant of the abdomen (Figures 3 and 4). Surgery was deferred and the child was observed until the cannula was passed out in the stool six days later. A modified barium swallow after four weeks was normal (Figures 5 and 6). In retrospect, the mother recalled that there had been unusual resistance on routine suctioning of the tracheotomy tube beginning one week prior to the incident.

\section{Discussion}

Tracheostomy is one of the oldest surgical procedures, and over the past decade has become the method of choice in management of patients with an impaired airway. ${ }^{3}$ Despite extra care and meticulous surgical technique, tracheostomy holds a complication rate of $5 \%$ to $40 \%{ }^{4}$ Categorized as late onset complications are suprastomal granulation tissue, tracheal stenosis/subglottic stenosis, tracheoesophageal fistula and, as in our case, a fractured tracheotomy tube. ${ }^{5}$

Fractures after prolonged usage longer than recommended may be due to mechanical (suctioning, cleaning, repeated removal) or chemical stress (corrosive cleaning fluids, alkaline

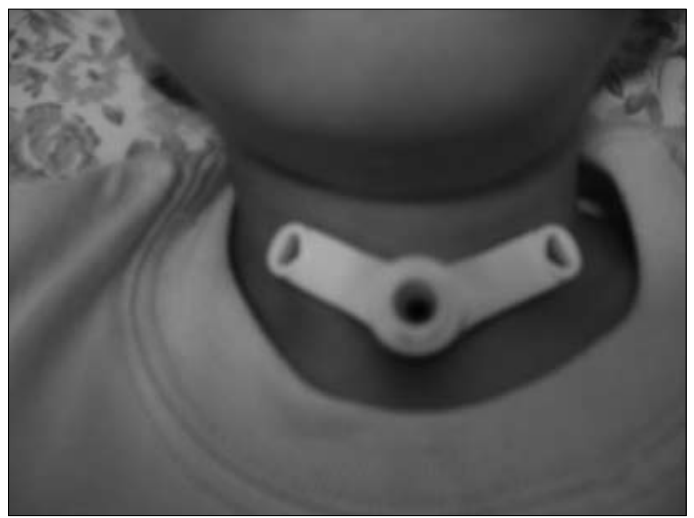

Figure 1. Tracheotomy tube apparently in place (re-enactment)

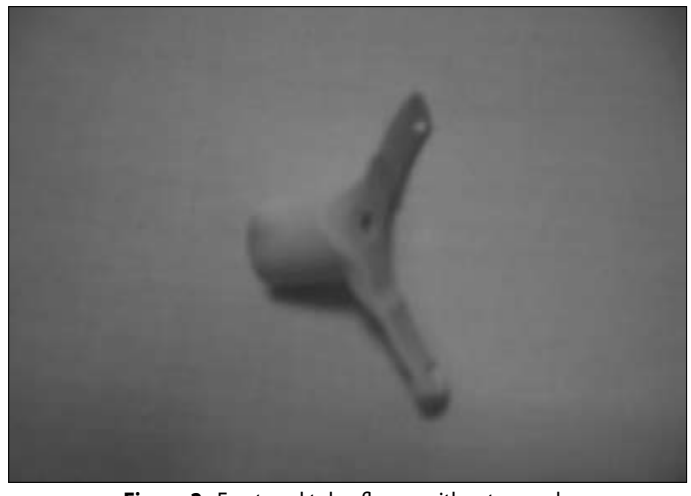

Figure 2. Fractured tube, flange without cannula

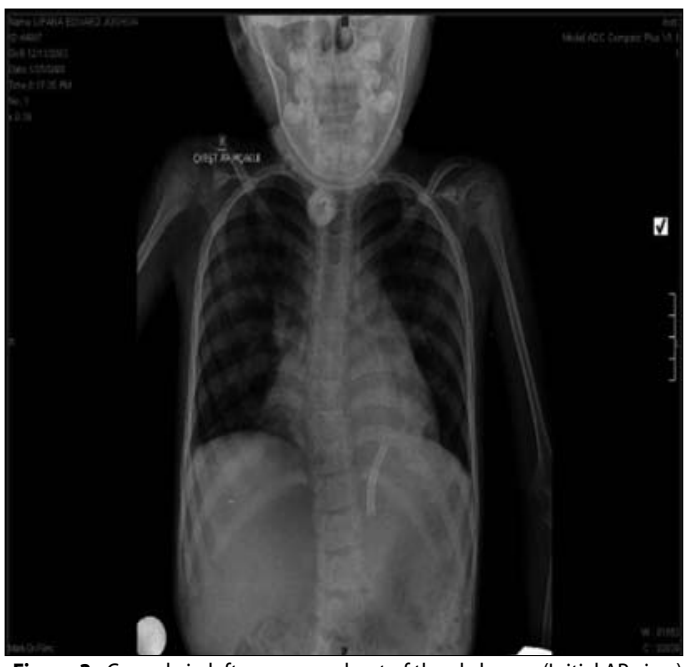

Figure 3. Cannula in left upper quadrant of the abdomen (Initial AP view)

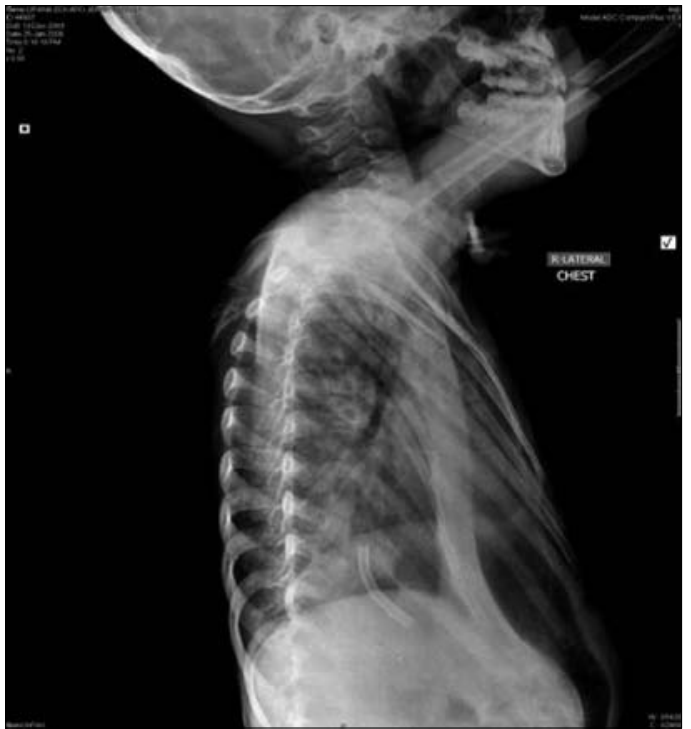

Figure 4. Cannula in left upper quadrant of the abdomen (Initial Lateral view) 


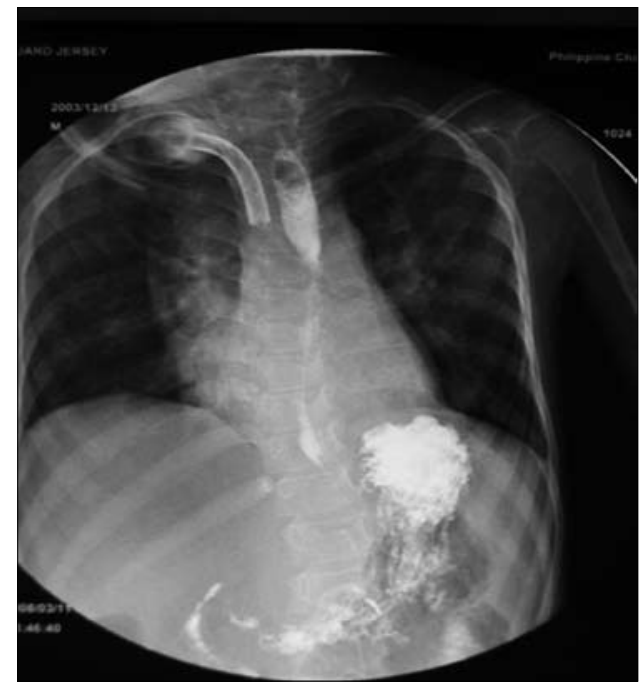

Figure 5. Barium swallow (AP view) - Entire length of esophagus shows normal distention No intrinsic lesion seen No unusual features noted

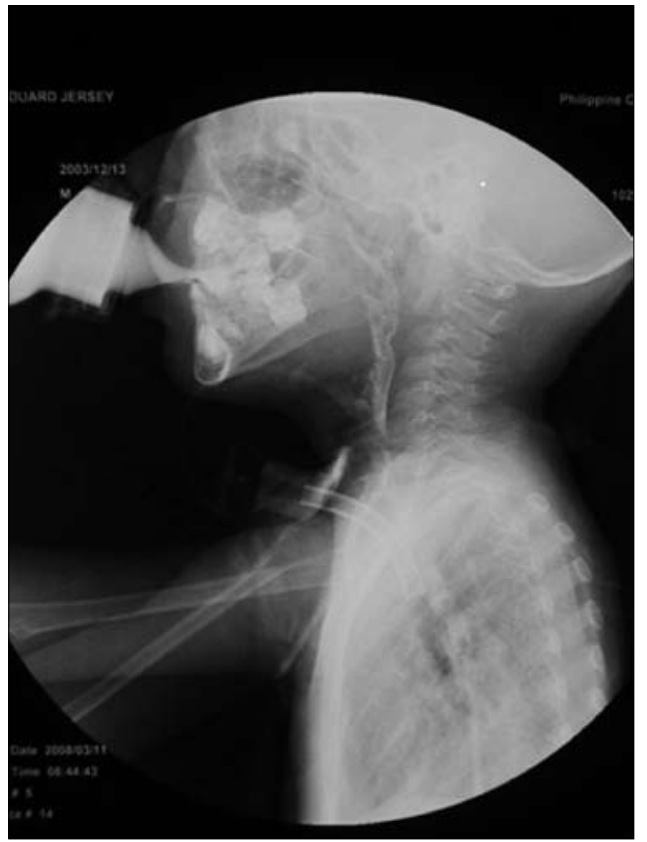

Figure 6. Barium swallow (Lateral view) -Normal motility and mucosal pattern

bronchial secretions). ${ }^{1,6}$ It has also been suggested that chemicals from plastic tubes may leach out causing tissue reactivity.' Death has been reported following fracture of a silver tracheotomy tube attributed to corrosion between the plate and shaft. ${ }^{2}$ In our case, the prolonged usage for almost four years predisposed to fracture, which may have been initially signaled by the increased resistance on suctioning one week prior to the emergency.

Previously reported cases of tracheostomy tube fracture in infants and adults all resulted in airway (tracheal or bronchial) foreign bodies. ${ }^{1,2,6,7}$ Choking and acute cough are the most common presenting symptoms and physical findings may range from reduced respiratory sounds, retraction from atelectasis, hyperdistension from obstructive emphysema to no changes at all. ${ }^{8}$ The classic triad of wheezing, coughing and unilateral reduced respiratory sounds occurs in most cases. ${ }^{9}$ On the other hand, esophageal foreign bodies may also present with coughing, vomiting, refractory wheeze, respiratory distress and stridor. $10,11,12$ Ingested foreign bodies distal to the esophagus are mostly asymptomatic, ${ }^{10,11}$ but other patients may present with abdominal pain, vomiting, fever, hematochezia or melena..$^{10}$ The fractured cannula, subcostal retractions and wheezing over both lung fields in our patient suggested aspiration.

Radiographs should be obtained prior to bronchoscopy even if they may appear normal in up to $50 \%$ of airway foreign bodies. ${ }^{13}$ In our case, they revealed the missing cannula in the abdomen and prevented unnecessary surgery as $90 \%$ of foreign bodies distal to the esophagus will pass spontaneously. ${ }^{12}$ Most objects pass within four to six days of ingestion (as in our case), although some may take up to four weeks. ${ }^{10}$ Weekly radiography and instructions to watch for passage of the object in stool are advised. ${ }^{10}$

The absence of a tracheoesophageal fistula (TEF) in our patient corroborated by a normal modified barium swallow after four weeks, leaves us with no other explanation for this unusual case: The patient coughed out the fractured cannula and ingested it.

In a developing country with limited access to health care, the importance of tracheotomy tube care and follow up cannot be overemphasized. Prolonged tracheotomy tube usage beyond recommended periods become commonplace when socio-economic considerations prevent regular consultations and periodic replacement. We hope our experience prompts increased vigilance and helps prevent similar incidents.

\section{REFERENCES}

1. Gana P, Takwoingi Y. Fractured Tracheostomy tubes in the Tracheobronchial tree of a child. Int J Pediatr Otolaryngol. 2000; 53 (1):45-48.

2. Gupta SC. Fratured Tracheostomy Tubes in the Tracheobronchial tree: A report of nine cases. J Laryngol Otol. 1987; 101 (8): 861-867.

3. Jackson C. Tracheostomy. Laryngoscope. 1909;19:285-290

4. Waldron J, Padgham ND, Hurley SE. Complications of emergency and elective tracheostomy: A retrospective study of 150 consecutive cases. Ann R Coll Surg Engl 1990; 72 (4):218-220

5. Cummings CW, Flint PW, Harker LA, Richardsons MA, Schuller DE, Robbins KT, Thomas JR, Haughey BH. Otolaryngol Head Neck Surg. 2005; 106: 2441-2452

6. Kumar KS, Das K, Dcruz AJ. Aspiration of a Cryptic Foreign Body (Tracheostomy tube flange). Indian J Pediatr 2004; 71 (12):1145-1146

7. Okafor BC. Fracture of tracheostomy tubes: Pathogenesis and prevention. J Laryngol Otol. 1983; 97 (8):771-774

8. Cataneo AJ, Cataneo DC, Ruiz RL Jr. Management of Tracheobronchial Foreign body in children. Pediatr Surg Int 2008; 24 (2): 151-156

9. Wiseman NE. The diagnosis of foreign body aspiration in childhood. J Pediatr Surg $1984 ; 19$ (5) : :531-535

10.Uyemura MC. Foreign Body Ingestion in Children. Am Fam Physician 2005;72 (2):287 292

11.Dashan A. Management of Ingested Foreign Bodies in Children. J Okla State Med Assoc 2001; 94 (6):183-6

12.Eisen GM, Baron TH, Dominitz JA, Faigel DO, Goldstein JL, Johanson JF, et al. Guideline for the Management of Ingested Foreign Bodies. Gastrointestinal Endoscopy 2002; 55 (7) : 802-806

13.Lone S, Lateef M. Foreign Body in Tracheobronchial tree. JK science. 2004; 6 (2): 77-80 